\title{
Association of CYP19A1 and CYP1A2 genetic polymorphisms with type 2 diabetes mellitus risk in the Chinese Han population
}

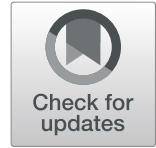

\author{
Yafeng Yang ${ }^{1}$ and Ping Wang ${ }^{2^{*}}$
}

\begin{abstract}
Background: Type 2 diabetes mellitus (T2DM), one of the global health issues, is a group of metabolic diseases and is affected by several genetic loci in the clinical phenotype. This study intended to ascertain associations between CYP19A1 and CYP1A2 gene polymorphisms with the T2DM risk in Chinese Han.

Methods: Seven single nucleotide polymorphisms (SNPs) in total including five of CYP19A1 (rs4646, rs6493487, rs1062033, rs17601876 and rs3751599) and two of CYP1A2 (rs762551 and rs2470890) from 512 T2DM patients and 515 non-diabetic controls were genotyped in the platform of Agena MassARRAY. SPSS 18.0 was utilized for analyzing genotyping results. Logistic regression models were conducted for the risk assessment by the odds ratios (ORs) and 95\% confidence intervals (Cls).

Results: The results suggested a significant association between genotype GC of rs 1062033 with a decreased T2DM risk $(\mathrm{OR}=0.73,95 \% \mathrm{Cl}=0.55-0.96, P=0.025)$ under the co-dominant (heterozygous) model. The results of stratification analysis with age and gender adjustment revealed that the effects of all selected SNPs in CYP19A1 and CYP1A2 on the T2DM susceptibility were dependent on age, body mass index (BMI) and disease progression $(P<0.05)$. The haplotype analysis was further conducted and the results indicated that $C_{\mathrm{rs} 1062033} \mathrm{G}_{\mathrm{rs} 17601876} \mathrm{~A}_{\mathrm{rs} 3751599}$ in CYP19A1 played a protective role $(\mathrm{OR}=0.48,95 \% \mathrm{Cl}=0.25-0.91, P=0.026)$ in T2DM patients with diabetic retinopathy.

Conclusion: This population-based case-control study suggested that CYP19A1 and CYP1A2 variations might affect the susceptibility of T2DM. The findings provide a theoretical basis for searching the clinical therapeutic markers and attractive drug targets of T2DM.
\end{abstract}

Keywords: CYP19A1, CYP1A2, Type 2 diabetes mellitus, Single nucleotide polymorphism

\section{Introduction}

Type 2 diabetes mellitus (T2DM) is a kind of chronic metabolic diseases characterized by chronic hyperglycemia arising from insulin secretion disorders, and/or the insulin resistance [1-3]. Besides, genetic predisposition, sedentary lifestyle, and excessive calorie intake

\footnotetext{
*Correspondence: 1140726733@qq.com

${ }^{2}$ Department of hemodialysis, Xianyang Central Hospital, Xianyang 712000, Shaanxi Province, China

Full list of author information is available at the end of the article
}

may also contribute to T2DM [4]. Studies have shown that the incidence of diabetes is related to genetic factors and is the result of the joint action of multiple gene loci $[4,5]$. Genome-wide association studies (GWAS), genome-wide linkage analysis and candidate-gene approaches are wildly applied in studying the genetic basis of T2DM $[1,3]$. To date, multiple genes have been functionally implicated in the pathogenesis of T2DM $[1,4]$. However, the susceptibility of T2DM varies across populations due to differences in interracial gene 
polymorphisms and haplotypes. Therefore, it is of great significance to expand the studies of T2DM susceptibility genes in different populations.

CYP19A1 locates at 15q21.2 containing 10 exons and spanning a 130-kb region, and encodes the aromatase enzyme which is associated with changes in aromatase levels [6]. Aromatase plays a crucial role in the final stage of estrogen biosynthesis, and can be affected by genetic factors resulting in the changes in serum sex hormone levels $[7,8]$, and recent evidences indicated that the rs4646 variant of CYP19A1 might be a predictive factor of the benefit of aromatase inhibitor treatment for breast cancer [9]. Meanwhile, CYP19A1 gene polymorphisms were considered to be related with coronary artery disease and circulating sex hormone levels in Chinese Uyghurs [10]. CYP19A1 was also found to be associated with cardiovascular risk factors such as insulin resistance and hypertension in a sex- and obesityspecific manner [11]. Recently, a case-control study on associations between CYP19A1 polymorphisms and obesity in Turkish population illustrated that the reduced aromatase activity is a risk factor for obesity, and CYP19A1 is associated with hyperandrogenism which may play a role in abdominal obesity pathogenesis [12]. The above studies confirmed that CYP19A1 may be associated with diabetic-related diseases. However, the relationship between CYP19A1 polymorphisms and the T2DM susceptibility has not been reported, especially in the population of Chinese Han.

CYP1A2 locates at $15 \mathrm{q} 24.1$ containing seven exons and six introns and spanning a 78-kb region, and encodes monooxygenase that can catalyze many reactions involved in drug metabolisms and synthesis of cholesterol, steroids and other lipids [13-15]. CYP1A2 is mainly expressed in mammalian liver, and participates in the metabolisms of over 100 substrates [13, 16]. Genetic polymorphisms of CYP1A2 have been extensively studied in a variety of populations, and were found to be involved in the etiology of developing cancers and other diseases [13, 16-19]. Moreover, a related study on CYP450 activities proved that the activity of CYP1A2 is slightly increased in the subjects with diabetes [20]. Previous studies also demonstrated that the enzyme activity of CYP1A2 and the speed of caffeine metabolism are increased in the T2DM group because of a higher caffeine intake [21]. The gene expression of CYP1A2 was also found to decrease in mice fed a high-fat diet [22]. In all above mentioned studies, researches have examined the functional activity of CYP1A2 in T2DM, but none of them focused on the genetic association.

To further investigate the role of CYP19A1 and CYP1A2 variations in the T2DM risk, this case-control study was set up to genotype 7 single nucleotide polymorphisms (SNPs) of T2DM patients and non-diabetic controls from the population of Chinese Han. The purpose of this study is to better understand the relationship between the population characteristics and the susceptibility to T2DM at the genetic level, and provide valuable diagnostic markers or targeted drug therapy strategies for T2DM by studying gene polymorphisms in the population of Chinese.

\section{Methods \\ Study population}

This case-control study involved 1027 participants comprising 512 patients with T2DM (54.9\% males, mean age $59.2 \pm 9.6$ years) and 515 non-diabetic controls $(55.0 \%$ males, mean age $59.3 \pm 11.0$ years) from the population of Chinese Han. Patients with T2DM were diagnosed according to the World Health Organization criteria (fast plasma glucose (FPG) $\geq 7.0 \mathrm{mmol} / \mathrm{L}$ and/or 2 -h plasma glucose $\geq 11.1 \mathrm{mmol} / \mathrm{L}$ ) and were recruited from September 2017 to June 2019. Cases with other diabetic types or treated by drugs (except anti-diabetic drugs) were excluded. The non-diabetic control subjects had normal glucose tolerance confirmed by $\mathrm{FPG} \leq 6.0 \mathrm{mmol} / \mathrm{L}$, or HbA1c levels $<6.5 \%$, and had no history of diabetes in first or second degree relatives. All participants signed the informed consents and authorization for blood sampling and banking. This study fully complied with the standard of Helsinki declaration and was permitted by the ethics committee of the First Affiliated Hospital of Xi'an Jiaotong University.

\section{SNP selection and genotyping}

Genomic DNA extraction was performed on the basis of the manufacturer's procedures of GoldMag Beads DNA Extraction Kit (GoldMag, Xi'an, Shaanxi, China). DNA concentration was determined by Spectrometry (Beckman Instruments, Fullerton, CA, USA). Agena MassARRAY platform (Agena Bioscience, San Diego, CA, USA) was utilized for SNP genotyping. The design of extended primers was conducted by the Agena online design software (https://agenacx.com/online-tools/), and the sequences were listed in Supplementary Table 1. The process of genotyping was double-blinded by two laboratory personnel. For quality control, $10 \%$ of the samples were randomly chosen for repeated genotyping, and the reproducibility was $100 \%$.

All seven candidate SNPs in CYP19A1 (rs4646, rs6493 487, rs1062033, rs17601876 and rs3751599) and CYP1 $A 2$ (rs762551 and rs2470890) were screened using the database of dbSNP in NCBI and the 1000 Genomes Project data, and the selection criteria were as follows: i) the minor allele frequency (MAF) of all SNPs was greater than 5\%; ii) call rate was over $95 \%$ during genotyping; iii) $r^{2}$, a pairwise linkage disequilibrium (LD), was over 0.8 . Besides, we applied RegulomeDB annotations to predict 
the effect of these SNPs according to the rank score evaluated by a model integrating functional genomic features.

\section{Statistical analysis}

The acquired data was statistically analyzed by SPSS 18.0 (SPSS, Chicago, IL, USA) and PLINK 1.07 packages. Differences in clinical characteristics between cases and controls were analyzed by Welch's t-test and Pearson's chi-squared test where appropriate. The allele and genotype frequencies in cases and controls were calculated by $X^{2}$ test. Hardy-Weinberg equilibrium (HWE) for each SNP in the control group was determined by fisher's exact test. Logistic analysis was performed to assess the correlation between the genetic variants and T2DM risk under allele, co-dominant, dominant, recessive and additive genetic models, respectively. Odds ratios (ORs) and 95\% confidence intervals (CIs) from a logistic regression model were calculated after adjusting for age and gender. The $P$ value (two-tailed) less than 0.05 indicated a statistical significance.

\section{Results}

\section{Demographics of study subjects and genotypic} characteristics of SNPs

In this study, seven SNPs of CYP19A1 and CYP1A2 from 512 T2DM patients and 515 non-diabetic controls were genotyped. The demographic details of the study subjects and the characteristic features of the studied SNPs were depicted in Tables 1 and 2, respectively. The frequency distributions of age $(P=0.990)$ and gender $(P=0.962)$ were matched between T2DM patients and non-diabetic controls.

All selected SNPs were consistent with HWE $(P>$ 0.05 ), and the MAFs of those were larger than 0.05 . The functional effects of SNPs were annotated by RegulomeDB, and were quantified by assigned rank scores accordingly. The results showed that rs2470890 of CYP1A2 was likely to affect expression quantitative trait loci (eQTL) + transcription factor (TF) binding/DNase peak, and was assigned a rank score of 1f. CYP19A1 rs3751599 was assigned a score of $2 \mathrm{~b}$ and might affect TF binding + any motif + DNase Footprint + DNase peak. The other SNPs were assigned 5-7, and were likely to influence TF binding or DNase peak or others. The lower the grade score, the greater impacts on gene features and regulatory elements. The frequency distributions of the allele and genotype were shown in Supplementary Table 2, and allele "A" was defined as the minor allele. These data were used to compare the distribution differences of genotypes between cases and controls in the following analysis.
Table 1 Demographics and clinical characteristics of cases and controls

\begin{tabular}{|c|c|c|c|}
\hline Variables & Case $(\boldsymbol{n}=512)$ & Control $(\boldsymbol{n}=515)$ & $P$ \\
\hline$\overline{\text { Age }}$ & $59.2 \pm 9.6$ & $59.3 \pm 11.0$ & $0.990^{\mathrm{a}}$ \\
\hline$\leq 59$ & 248 & 243 & \\
\hline$>59$ & 264 & 272 & \\
\hline Gender & & & $0.962^{b}$ \\
\hline Male & 281 & 283 & \\
\hline Female & 231 & 232 & \\
\hline \multicolumn{4}{|l|}{ BMI } \\
\hline$\leq 24$ & 130 & 126 & \\
\hline$>24$ & 190 & 123 & \\
\hline \multicolumn{4}{|c|}{ Tobacco smoking status } \\
\hline Yes & 135 & 132 & \\
\hline No & 231 & 137 & \\
\hline \multicolumn{4}{|c|}{ Alcohol consumption status } \\
\hline Yes & 69 & 98 & \\
\hline No & 278 & 138 & \\
\hline \multicolumn{4}{|l|}{ Disease course } \\
\hline$\leq 9$ & 151 & & \\
\hline$>9$ & 186 & & \\
\hline \multicolumn{4}{|l|}{ Complication } \\
\hline one & 108 & & \\
\hline multiple & 141 & & \\
\hline \multicolumn{4}{|c|}{ Antidiabetes drug } \\
\hline Yes & 128 & & \\
\hline No & 204 & & \\
\hline \multicolumn{4}{|l|}{ Insulin } \\
\hline Yes & 175 & & \\
\hline No & 157 & & \\
\hline \multicolumn{4}{|c|}{ Diabetic retinopathy } \\
\hline Yes & 213 & & \\
\hline No & 149 & & \\
\hline $\mathrm{FPG}(\mathrm{mmol} / \mathrm{L})$ & $9.95 \pm 4.69$ & $5.67 \pm 0.78$ & $<0.001^{a^{*}}$ \\
\hline $\mathrm{HbA1c}(\%)$ & $9.30 \pm 2.47$ & $5.88 \pm 0.79$ & $0.004^{\mathrm{a}^{*}}$ \\
\hline
\end{tabular}

The clinical information of participants was partially missing except age, gender and $\mathrm{FPG} / \mathrm{HbA} 1 \mathrm{c}$ indexes

$B M I$ body mass index, FPG fasting plasma glucose, HbA1c Hemoglobin A1c ${ }^{\mathrm{a}} P$ was calculated by $\mathrm{t}$ test

${ }^{\mathrm{b}} P$ was calculated by Pearson's chi-squared test

${ }^{*} P<0.05$ indicates a significant difference

\section{Association of CYP19A1 and CYP1A2 polymorphisms with the T2DM susceptibility}

To evaluate the allelic and genotypic distributions of all seven SNPs in CYP19A1 and CYP1A2, inheritance models were established and the relevant results were organized in Table 3. Only GC genotype of rs1062033 in CYP19A1 was detected to be significantly associated with a decreased risk of T2DM under the co-dominant 
Table 2 Information and function annotation of SNPs in CYP19A1 and CYP1A2

\begin{tabular}{|c|c|c|c|c|c|c|c|c|c|c|c|}
\hline \multirow[t]{2}{*}{ Gene } & \multirow[t]{2}{*}{ SNP } & \multirow[t]{2}{*}{ Chromosome } & \multirow[t]{2}{*}{ Position } & \multirow{2}{*}{$\begin{array}{l}\text { Allele } \\
\text { A/B }\end{array}$} & \multirow[t]{2}{*}{ Role } & \multicolumn{2}{|l|}{ MAF } & \multirow[t]{2}{*}{$p$-HWE } & \multirow[t]{2}{*}{ ORs $(95 \% \mathrm{Cl})$} & \multirow[t]{2}{*}{$P$} & \multirow{2}{*}{$\begin{array}{l}\text { RegulomeDE } \\
\text { Rank }\end{array}$} \\
\hline & & & & & & Case & Control & & & & \\
\hline CYP19A1 & rs4646 & 15 & $51,210,647$ & $\mathrm{~A} / \mathrm{C}$ & Intron & 0.314 & 0.291 & 0.669 & $1.12(0.92-1.35)$ & 0.257 & 5 \\
\hline CYP19A1 & rs6493487 & 15 & $51,221,532$ & $\mathrm{G} / \mathrm{A}$ & Intron & 0.288 & 0.265 & 0.734 & $1.12(0.93-1.37)$ & 0.236 & 6 \\
\hline CYP19A1 & rs1062033 & 15 & $51,255,741$ & $\mathrm{G} / \mathrm{C}$ & 5' UTR & 0.432 & 0.448 & 0.110 & $0.94(0.79-1.12)$ & 0.464 & 5 \\
\hline CYP19A1 & rs17601876 & 15 & $51,261,712$ & $A / G$ & Intron & 0.341 & 0.334 & 0.921 & $1.03(0.86-1.24)$ & 0.743 & 7 \\
\hline CYP19A1 & rs3751599 & 15 & $51,281,336$ & $A / G$ & Intron & 0.058 & 0.074 & 1 & $1.07(0.54-1.09)$ & 0.139 & $2 b$ \\
\hline CYP1A2 & rs762551 & 15 & $74,749,576$ & $C / A$ & Intron & 0.402 & 0.414 & 0.928 & $0.95(0.80-1.14)$ & 0.595 & 5 \\
\hline CYP1A2 & rs2470890 & 15 & $74,755,085$ & $\mathrm{~T} / \mathrm{C}$ & $\begin{array}{l}\text { Coding } \\
\text { sequence }\end{array}$ & 0.121 & 0.115 & 0.187 & $1.07(0.81-1.39)$ & 0.646 & if \\
\hline
\end{tabular}

SNP single nucleotide polymorphism, MAF minor allele frequency, HWE Hardy-Weinberg Equilibrium, OR odds ratio, 95\% CI 95\% confidence interval Rank 1f, eQTL + TF binding / DNase peak; Rank 2b, TF binding + any motif + DNase Footprint + DNase peak; Rank 5, TF binding or DNase peak; Rank 6-7, other

(heterozygous) model (OR $=0.73,95 \% \mathrm{CI}=0.55-0.96$, $P=0.025)$. The association between the clinical indexes of T2DM and the CYP19A1 rs1062033 polymorphism was further analyzed, but no significant correlation was observed (Supplementary Table 3).

\section{Stratification analysis to assess the association between CYP19A1 and CYP1A2 polymorphisms and the T2DM risk} Stratification analyses on age, gender, smoking status and drinking status between T2DM patients and nondiabetic controls, as well as the disease course and the occurrence of retinopathy in T2DM patients were then carried out to further investigate the relevance between SNPs and the T2DM risk. The data were collected after adjustment of age and gender, and were summarized in Table 4. The results suggested that in the population over 59 years old, the T2DM risk was increased in AA carriers at r4646 under both co-dominant (homozygous) and recessive models $(\mathrm{OR}=2.01,95 \% \mathrm{CI}=1.03-3.94$, $P=0.041$ and $\mathrm{OR}=2.10,95 \% \mathrm{CI}=1.10-4.02, P=0.026$, respectively), and in GG carriers at rs6493487 under the recessive model $(\mathrm{OR}=2.09,95 \% \mathrm{CI}=1.07-4.08, \quad P=$ 0.032), as well as in AA carriers at rs17601876 under the recessive model $(\mathrm{OR}=1.86,95 \% \mathrm{CI}=1.01-3.43, \quad P=$ 0.048). However, rs1062033 in CYP19A1 was found to be associated with a decreased risk of T2DM under GC genotype of co-dominant ( $\mathrm{OR}=0.50,95 \% \mathrm{CI}=0.33-$ $0.75, P=0.001)$ and dominant models $(\mathrm{OR}=0.59,95 \%$ $\mathrm{CI}=0.40-0.87, \quad P=0.008)$. Besides, $\mathrm{CC}$ genotype of rs762551 in gene CYP1A2 was also found to be associated with a decreased risk of T2DM under the recessive model $(\mathrm{OR}=0.55,95 \% \mathrm{CI}=0.33-0.92, P=0.023)$ but in the population less than 59 years old.

Meanwhile, significant associations were found between CYP19A1 rs3751599 and the decreased risk of retinopathy in T2DM patients under the allelic $(\mathrm{OR}=0.53$, 95\% $\mathrm{CI}=0.29-0.99, P=0.044)$, dominant $(\mathrm{OR}=0.51$, $95 \% \mathrm{CI}=0.26-0.98, P=0.045)$ and additive $(\mathrm{OR}=0.50$,
95\% CI $=0.26-0.95, P=0.034)$ models. The results based on individuals with body mass index (BMI) over $24 \mathrm{~kg} /$ $\mathrm{m}^{2}$ suggested that $C Y P 1 A 2$ rs762551 served as a protective factor of T2DM under the allelic model $(\mathrm{OR}=0.70$, 95\% CI $=0.49-1.00, P=0.047)$, co-dominant model with $\mathrm{CC}$ genotype $(\mathrm{OR}=0.32,95 \% \mathrm{CI}=0.14-0.74, P=0.006)$, recessive model $(\mathrm{OR}=0.31,95 \% \mathrm{CI}=0.14-0.66, \quad P=$ $0.002)$ and additive model $(\mathrm{OR}=0.67,95 \% \mathrm{CI}=0.46-$ $0.96, P=0.031)$. The related results also suggested that carriers with heterozygous variant allele at rs2470890 of CYP1A2 decreased 0.54-fold risk of T2DM among patients with disease course over 9 years.

\section{Haplotype analysis}

The haplotype analysis on CYP19A1 and CYP1A2 polymorphisms (Table 5) results in the generation of two haplotype blocks that contains rs17601876 and rs3751599 of CYP19A1 in block 1, and rs762551 and rs2470890 of CYP1A2 in block 2. However, no significant association was detected between the haplotypes and T2DM risk. Furthermore, on the basis of stratification analysis results, haplotype $C_{\text {rs1062033 }} G_{\text {rs17601876 }} A_{\text {rs375 }}$ 1599 in CYP19A1 was found to be associated with the decreased risk of retinopathy in T2DM patients.

\section{Discussion}

T2DM is a complicated and multi-factorial disease, and is a serious threat to global public health. It was reported that in China there are over 100 million patients with diabetes and the prevalence rate is still on the rise [22]. Therefore, this population-based case-control study was set up, and firstly demonstrated the effects of CYP19A1 and CYP1A2 gene polymorphisms on the T2DM susceptibility.

The results suggested that CYP19A1 rs1062033 was correlated with the decreased risk of T2DM, and acted as a protective factor of T2DM in patients less than 59 years old. However, by studying the the population of 
Table 3 Association of CYP19A1 and CYP1A2 polymorphisms with T2DM risk

\begin{tabular}{|c|c|c|c|c|c|}
\hline Gene & SNP & Model & Allele/Genotype & $\mathrm{OR}(95 \% \mathrm{Cl})$ & $P$ \\
\hline \multirow[t]{6}{*}{ CYP19A1 } & rs4646 & Allele & $A$ & $1.12(0.92-1.35)$ & 0.257 \\
\hline & & Co-dominant (HOM) & AA vs CC & $1.42(0.91-2.20)$ & 0.121 \\
\hline & & Co-dominant (HET) & $A C$ vs $C C$ & $1.00(0.77-1.30)$ & 0.982 \\
\hline & & Dominant & $A A-A C$ vs CC & $1.07(0.84-1.37)$ & 0.596 \\
\hline & & Recessive & AA vs AC-CC & $1.41(0.93-2.16)$ & 0.109 \\
\hline & & Additive & & $1.11(0.92-1.34)$ & 0.260 \\
\hline \multirow[t]{6}{*}{ CYP19A1 } & rs6493487 & Allele & G & $1.12(0.93-1.37)$ & 0.236 \\
\hline & & Co-dominant (HOM) & GG vs AA & $1.52(0.95-2.42)$ & 0.633 \\
\hline & & Co-dominant (HET) & GA vs $A A$ & $0.99(0.76-1.28)$ & 0.936 \\
\hline & & Dominant & GG-GA vs AA & $1.07(0.83-1.36)$ & 0.616 \\
\hline & & Recessive & GG vs GA-AA & $1.52(0.97-2.40)$ & 0.070 \\
\hline & & Additive & & $1.12(0.93-1.36)$ & 0.242 \\
\hline \multirow[t]{6}{*}{ CYP19A1 } & rs1062033 & Allele & G & $0.94(0.79-1.12)$ & 0.464 \\
\hline & & Co-dominant (HOM) & GG vs CC & $0.94(0.66-1.34)$ & 0.736 \\
\hline & & Co-dominant (HET) & GC vs CC & $0.73(0.55-0.96)$ & $0.025^{*}$ \\
\hline & & Dominant & GG-GC vs CC & $0.78(0.60-1.02)$ & 0.067 \\
\hline & & Recessive & GG vs GC-CC & $1.14(0.84-1.56)$ & 0.395 \\
\hline & & Additive & & $0.94(0.79-1.12)$ & 0.463 \\
\hline \multirow[t]{6}{*}{ CYP19A1 } & rs17601876 & Allele & A & $1.03(0.86-1.24)$ & 0.743 \\
\hline & & Co-dominant (HOM) & $A A$ vs $G G$ & $1.06(0.71-1.59)$ & 0.771 \\
\hline & & Co-dominant (HET) & $A G$ vs $G G$ & $1.03(0.80-1.34)$ & 0.816 \\
\hline & & Dominant & AA-AG vs GG & $1.04(0.81-1.33)$ & 0.769 \\
\hline & & Recessive & $A A$ vs $A G-G G$ & $1.05(0.71-1.54)$ & 0.820 \\
\hline & & Additive & & $1.03(0.86-1.24)$ & 0.744 \\
\hline \multirow[t]{6}{*}{ CYP19A1 } & rs3751599 & Allele & A & $1.07(0.54-1.09)$ & 0.139 \\
\hline & & Co-dominant (HOM) & $A A$ vs $G G$ & $0.48(0.04-5.37)$ & 0.555 \\
\hline & & Co-dominant (HET) & $A G$ vs $G G$ & $0.77(0.53-1.12)$ & 0.166 \\
\hline & & Dominant & AA-AG vs $G G$ & $0.76(0.53-1.10)$ & 0.146 \\
\hline & & Recessive & $A A$ vs $A G-G G$ & $0.50(0.05-5.55)$ & 0.573 \\
\hline & & Additive & & $0.76(0.53-1.09)$ & 0.136 \\
\hline \multirow[t]{6}{*}{ CYPIA2 } & rs762551 & Allele & C & $0.95(0.80-1.14)$ & 0.595 \\
\hline & & Co-dominant (HOM) & CC vs AA & $0.82(0.56-1.20)$ & 0.315 \\
\hline & & Co-dominant (HET) & CA vs AA & $1.14(0.87-1.50)$ & 0.339 \\
\hline & & Dominant & CC-CA vs AA & $1.06(0.82-1.37)$ & 0.672 \\
\hline & & Recessive & $C C$ vs CA-AA & $0.76(0.54-1.07)$ & 0.116 \\
\hline & & Additive & & $0.95(0.79-1.14)$ & 0.587 \\
\hline \multirow[t]{6}{*}{ CYP1A2 } & rs2470890 & Allele & $\mathrm{T}$ & $1.07(0.81-1.39)$ & 0.646 \\
\hline & & Co-dominant (HOM) & TT vs CC & $0.42(0.13-1.34)$ & 0.140 \\
\hline & & Co-dominant (HET) & TC vs CC & $1.23(0.91-1.66)$ & 0.182 \\
\hline & & Dominant & TT-TC vs CC & $1.15(0.86-1.55)$ & 0.342 \\
\hline & & Recessive & TT vs TC-CC & $0.40(0.12-1.28)$ & 0.121 \\
\hline & & Additive & & $1.07(0.81-1.39)$ & 0.646 \\
\hline
\end{tabular}

SNP single nucleotide polymorphism, OR odds ratio, 95\% Cl 95\% confidence interval, HOM homozygous, HET heterozygous $P$ value was calculated by logistic regression analysis with adjustment for age and gender 
Table 4 Stratification analysis on CYP19A1 and CYP1A2 polymorphisms and T2DM risk

\begin{tabular}{|c|c|c|c|c|c|c|c|c|c|c|c|c|c|}
\hline \multirow[t]{2}{*}{ SNP } & \multirow[t]{2}{*}{ Subgroups } & \multicolumn{2}{|l|}{$\begin{array}{l}\text { Co-dominant } \\
(\mathrm{HOM})\end{array}$} & \multicolumn{2}{|l|}{$\begin{array}{l}\text { Co-dominant } \\
\text { (HET) }\end{array}$} & \multicolumn{2}{|l|}{ Dominant } & \multicolumn{2}{|l|}{ Recessive } & \multicolumn{2}{|l|}{ Additive } & \multicolumn{2}{|l|}{ Allele } \\
\hline & & OR $(95 \% \mathrm{Cl})$ & $P$ & OR $(95 \% \mathrm{Cl})$ & $P$ & OR $(95 \% \mathrm{Cl})$ & $P$ & OR $(95 \%$ Cl) & $P$ & OR $(95 \% \mathrm{Cl})$ & $P$ & OR $(95 \% \mathrm{Cl})$ & $P$ \\
\hline \multicolumn{14}{|l|}{ CYP19A1 } \\
\hline rs4646 & Age $(\leq 59)$ & $\begin{array}{l}2.01 \\
(1.03-3.94)\end{array}$ & $0.041^{*}$ & $\begin{array}{l}0.91 \\
(0.63-1.33)\end{array}$ & 0.633 & $\begin{array}{l}1.05 \\
(0.73-1.50)\end{array}$ & 0.789 & $\begin{array}{l}2.10 \\
(1.10-4.02)\end{array}$ & $0.026^{*}$ & $\begin{array}{l}1.19 \\
(0.90-1.56)\end{array}$ & 0.226 & $\begin{array}{l}1.20 \\
(0.92-1.58)\end{array}$ & 0.185 \\
\hline rs6493487 & Age $(\leq 59)$ & $\begin{array}{l}1.96 \\
(0.98-3.91)\end{array}$ & 0.055 & $\begin{array}{l}0.86 \\
(0.59-1.26)\end{array}$ & 0.442 & $\begin{array}{l}1.00 \\
(0.70-1.43)\end{array}$ & 0.997 & $\begin{array}{l}2.09 \\
(1.07-4.08)\end{array}$ & $0.032^{*}$ & $\begin{array}{l}1.14 \\
(0.87-1.51)\end{array}$ & 0.345 & $\begin{array}{l}1.17 \\
(0.88-1.55)\end{array}$ & 0.280 \\
\hline rs1062033 & Age $(\leq 59)$ & $\begin{array}{l}0.93 \\
(0.55-1.57)\end{array}$ & 0.783 & $\begin{array}{l}0.50 \\
(0.33-0.75)\end{array}$ & $0.001^{*}$ & $\begin{array}{l}0.59 \\
(0.40-0.87)\end{array}$ & $0.008^{*}$ & $\begin{array}{l}1.41 \\
(0.89-2.23)\end{array}$ & 0.149 & $\begin{array}{l}0.88 \\
(0.68-1.14)\end{array}$ & 0.333 & $\begin{array}{l}0.88 \\
(0.68-1.13)\end{array}$ & 0.319 \\
\hline rs17601876 & Age $(\leq 59)$ & $\begin{array}{l}1.79 \\
(0.94-3.40)\end{array}$ & 0.076 & $\begin{array}{l}0.93 \\
(0.64-1.35)\end{array}$ & 0.690 & $\begin{array}{l}1.04 \\
(0.73-1.49)\end{array}$ & 0.818 & $\begin{array}{l}1.86 \\
(1.01-3.43)\end{array}$ & $0.048^{*}$ & $\begin{array}{l}1.16 \\
(0.89-1.53)\end{array}$ & 0.275 & $\begin{array}{l}1.17 \\
(0.89-1.53)\end{array}$ & 0.254 \\
\hline rs3751599 & $\begin{array}{l}\text { Diabetic } \\
\text { retinopathy }\end{array}$ & - & - & $\begin{array}{l}0.53 \\
(0.27-1.04)\end{array}$ & 0.064 & $\begin{array}{l}0.51 \\
(0.26-0.98)\end{array}$ & $0.045^{*}$ & - & - & $\begin{array}{l}0.50 \\
(0.26-0.95)\end{array}$ & $0.034^{*}$ & $\begin{array}{l}0.53 \\
(0.29-0.99)\end{array}$ & $0.044^{*}$ \\
\hline \multicolumn{14}{|l|}{ CYP1A2 } \\
\hline \multirow[t]{2}{*}{ rs762551 } & Age (> 59) & $\begin{array}{l}0.63 \\
(0.36-1.10)\end{array}$ & 0.106 & $\begin{array}{l}1.21 \\
(0.82-1.78)\end{array}$ & 0.344 & $\begin{array}{l}1.06 \\
(0.73-1.54)\end{array}$ & 0.771 & $\begin{array}{l}0.55 \\
(0.33-0.92)\end{array}$ & $0.023^{*}$ & $\begin{array}{l}0.87 \\
(0.67-1.13)\end{array}$ & 0.299 & $\begin{array}{l}0.88 \\
(0.69-1.12)\end{array}$ & 0.290 \\
\hline & $\mathrm{BMI}(\leq 24)$ & $\begin{array}{l}0.32 \\
(0.14-0.74)\end{array}$ & $0.006^{*}$ & $\begin{array}{l}1.07 \\
(0.62-1.86)\end{array}$ & 0.799 & $\begin{array}{l}0.81 \\
(0.49-1.36)\end{array}$ & 0.424 & $\begin{array}{l}0.31 \\
(0.14-0.66)\end{array}$ & $0.002^{*}$ & $\begin{array}{l}0.67 \\
(0.46-0.96)\end{array}$ & $0.031^{*}$ & $\begin{array}{l}0.70 \\
(0.49-1.00)\end{array}$ & $0.047^{*}$ \\
\hline rs2470890 & $\begin{array}{l}\text { Disease } \\
\text { course }(>9)\end{array}$ & - & - & $\begin{array}{l}0.54 \\
(0.31-0.95)\end{array}$ & $0.033^{*}$ & $\begin{array}{l}0.61 \\
(0.35-1.06)\end{array}$ & 0.077 & - & - & $\begin{array}{l}0.72 \\
(0.43-1.20)\end{array}$ & 0.208 & $\begin{array}{l}0.77 \\
(0.48-1.25)\end{array}$ & 0.290 \\
\hline
\end{tabular}

\footnotetext{
SNP single nucleotide polymorphism, OR odds ratio, 95\% Cl 95\% confidence interval, HOM homozygous, HET heterozygous, BMI body mass index

"_" indicates no results

$P$ value was calculated by logistic regression analysis with adjustment for age and gender

${ }^{*} P<0.05$ indicates statistical significance
}

Chinese Han over 64 years old, Wang et al. suggested that rs1062033 might increase the risk of stroke [23]. Kopp et al. also found that rs1062033 is associated with alcohol dependence differences in estrone sulphate levels [24], but in the stratified analysis of this study, the relationship between this locus and the alcohol consumption was not observed. To the best of our knowledge, there were limited studies on CYP19A1 rs1062033 and no related finding in diabetes has been reported to date. Therefore, based on the findings in this study, genotype GC of CYP19A1 rs1062033 was speculated to be of protective importance in T2DM patients especially in the population less than 59 years old.
According to the database of RegulomeDB, CYP19A1 rs3751599 and CYP1A2 rs2470890 were assigned rank scores of $1 \mathrm{f}$ and $2 \mathrm{~b}$, respectively. These two loci were considered to locate in crucial areas of genomic function such as eQTL, TF binding sites and DNase hypersensitivity regions that may affect the protein binding and the expression of target genes. This study proved that rs3751599 was associated with a decreased risk of retinopathy in T2DM patients, and rs2470890 could also decrease the risk of T2DM in patients with disease course over 9 years. A GWAS study in Chinese Han illustrated that rs3751599 is a human height-related SNP in CYP19A1 locus [25]. CYP1A2 rs2470890 polymorphisms have been studied in breast

Table 5 Association of CYP19A1 and CYP1A2 haplotypes with T2DM risk

\begin{tabular}{|c|c|c|c|c|c|c|c|}
\hline Subgroup & Gene & SNP & Haplotype & Fre-case & Fre-control & $\mathrm{OR}(95 \% \mathrm{Cl})$ & $P$ \\
\hline \multirow[t]{6}{*}{ Overall } & \multirow[t]{3}{*}{ CYP19A1 } & \multirow[t]{3}{*}{ rs17601876|rs3751599 } & GA & 0.058 & 0.074 & $0.76(0.53-1.09)$ & 0.136 \\
\hline & & & $A G$ & 0.341 & 0.334 & $1.03(0.86-1.24)$ & 0.744 \\
\hline & & & GG & 0.398 & 0.408 & $0.96(0.81-1.15)$ & 0.666 \\
\hline & \multirow[t]{3}{*}{ CYP1A2 } & \multirow[t]{3}{*}{ rs762551|rs2470890 } & AT & 0.120 & 0.114 & $1.07(0.81-1.40)$ & 0.640 \\
\hline & & & $\mathrm{CC}$ & 0.401 & 0.413 & $0.95(0.79-1.14)$ & 0.586 \\
\hline & & & $A C$ & 0.478 & 0.473 & $1.02(0.86-1.21)$ & 0.825 \\
\hline \multirow[t]{4}{*}{ Diabetic retinopathy } & \multirow[t]{4}{*}{ CYP19A1 } & \multirow[t]{4}{*}{ rs1062033|rs17601876|rs3751599 } & CGA & 0.042 & 0.081 & $0.48(0.25-0.91)$ & $0.026^{*}$ \\
\hline & & & CAG & 0.330 & 0.352 & $0.90(0.65-1.23)$ & 0.509 \\
\hline & & & GGG & 0.429 & 0.409 & $1.05(0.79-1.41)$ & 0.725 \\
\hline & & & CGG & 0.196 & 0.151 & $1.45(0.97-2.18)$ & 0.072 \\
\hline
\end{tabular}

SNP single nucleotide polymorphism, OR odds ratio, 95\% Cl 95\% confidence interval $P$ value was calculated by logistic regression analysis with adjustment for age and gender ${ }^{*} P<0.05$ indicates statistical significance 
cancer of northern China, and in depression of Chinese Han, as well as in pharmacogenomics analysis among Chinese [26-28]. However, neither of these two SNPs were investigated in T2DM, and this is the first study to carry out the data-based association analysis and found their protective effects on T2DM in certain populations.

In the published articles, CYP19A1 rs4646 and CYP1A2 rs762551 were extensively studied. Umamaheswaran et al. found that the allele and genotype frequencies of CYP19A1 rs4646 were significantly different in South Indians and Hans Chinese in Beijing, indicating a statistically significant inter-ethnic difference of rs4646 polymorphism [29]. Therefore, it is meaningful to study the relationship between rs4646 polymorphism and the specific disease in the population of Chinese Han. CYP19A1 rs4646 was wildly discussed in estrogen-related diseases, and the rs4646 polymorphism was believed to affect the aromatase activity and the effect of estrogen [30]. Meanwhile, De et al. highlighted the protective role of estrogen in diabetes and illustrated gender differences in the performance and outcome of diabetes based on clinical and preclinical data [31]. However, no significant association was found between gender and the rs4646 polymorphism in this study, but the relevant findings suggested that the effect of the rs4646 polymorphism on the T2DM risk was dependent on age. The rs762551 (CYP1A2*1F; $-163 \mathrm{C}>\mathrm{A})$ polymorphism in intron 1 of $C Y P 1 A 2$ at position 734 downstream of the first transcribed nucleotide was reported to associate with caffeine intake in different genders and ethnicities [32, 33], and to play a role in lipid metabolism thereby indicating a participation in age-related macular degeneration [34]. By studying the T2DM patients, results of this study indicated that the contribution of the rs762551 polymorphism was age-related but not genderrelated. Besides, this study also found the rs762551 polymorphism was the protective factor for the population with a BMI less than $24 \mathrm{~kg} / \mathrm{m}^{2}$. However, further functional study is still necessary to investigate the role of these SNPs in the risk of T2DM.

\section{Study strengths and limitations}

This is the first study to explore the effects of CYP19A1 and CYP1A2 on T2DM in the population of Chinese $H a n$, and reported that the influence of the genetic polymorphisms of CYP19A1 and CYP1A2 on the risk of T2DM may be related to age, BMI and disease course. However, the limitations of this study included the lack of sample size and the loss of information regarding habitual consumption of some dietary components known to affect CYP19A1 and CYP1A2 activities. To further explore the susceptibility loci of T2DM, larger sample collections are needed, and joint actions of environmental factors including lifestyle, dietary and climates have to be taken into consideration.

\section{Conclusion}

To conclude, this study put forward some associations between CYP19A1 and CYP1A2 gene polymorphisms with the T2DM susceptibility under different genetic models, and suggested the potential role of CYP19A1 and CYP1A2 variations with T2DM risk among the Chinese Han population. This study provides new insights into the search for drug therapy targets, but subsequent mechanism studies are still needed to enrich the results.

\section{Supplementary information}

Supplementary information accompanies this paper at https://doi.org/10. 1186/s12944-020-01366-9.

Additional file 1: Supplementary Table 1. Sequences of oligonucleotide primers used to analysis gene polymorphisms. Supplementary Table $\mathbf{2}$. Frequency distributions of the allele and genotype of SNPS in CYP19A1 and CYP1A2. Supplementary Table 3 Association analysis on clinical indexes of T2DM and CYP19A1 rs1062033 polymorphisms

\section{Abbreviations}

T2DM: Type 2 diabetes mellitus; GWAS: Genome-wide association study; SNP: Single nucleotide polymorphism; FPG: Fast plasma glucose; MAF: Minor allele frequency; LD: Linkage disequilibrium; HWE: Hardy-Weinberg equilibrium; OR: Odds ratio; Cl: Confidence interval; eQTL: Expression quantitative trait loci; TF: Transcription factor; BMl: Body mass index

\section{Acknowledgements}

We appreciate all participants in the First Affiliated Hospital of Xi'an Jiaotong University for their kind donation and cooperation.

\section{Authors' contributions}

Yafeng Yang contributed to the conceptualization, methodology, data analysis and manuscript writing. Ping Wang contributed to the conceptualization, resources, manuscript review and editing and supervision. All authors have read and approved the final version of this manuscript.

Funding

Not applicable.

Availability of data and materials

All data obtained from the current study are available from the corresponding author upon reasonable request.

Ethics approval and consent to participate

All procedures involving human participants in this study met ethical standards of the Helsinki declaration and its subsequent amendments. This study was approved by the First Affiliated Hospital of Xi'an Jiaotong University and informed consents were delivered and signed by all participants.

Consent for publication

Not applicable.

Competing interests

The authors declare that they have no competing interests.

Author details

${ }^{1}$ Department of clinical nutrition, Xianyang Central Hospital, Xianyang 712000, Shaanxi Province, China. ${ }^{2}$ Department of hemodialysis, Xianyang Central Hospital, Xianyang 712000, Shaanxi Province, China. 
Received: 5 May 2020 Accepted: 10 August 2020 Published online: 19 August 2020

\section{References}

1. Bao XY, Peng B, Yang MS. Replication study of novel risk variants in six genes with type 2 diabetes and related quantitative traits in the Han Chinese lean individuals. Mol Biol Rep. 2012;39:2447-54.

2. Lee YH, Kang ES, Kim SH, Han SJ, Kim CH, Kim HJ, Ahn CW, Cha BS, Nam M, Nam CM, Lee HC. Association between polymorphisms in SLC30A8, HHEX, CDKN2A/B, IGF2BP2, FTO, WFS1, CDKAL1, KCNQ1 and type 2 diabetes in the Korean population. J Hum Genet. 2008;53:991-8.

3. Sanghera DK, Ortega L, Han S, Singh J, Ralhan SK, Wander GS, Mehra NK, Mulvihill JJ, Ferrell RE, Nath SK, Kamboh MI. Impact of nine common type 2 diabetes risk polymorphisms in Asian Indian Sikhs: PPARG2 (Pro12Ala), IGF2BP2, TCF7L2 and FTO variants confer a significant risk. BMC Med Genet. 2008;9:59.

4. Nikitin AG, Potapov $\mathrm{W}$, Brovkina OI, Koksharova EO, Khodyrev DS, Philippov YI, Michurova MS, Shamkhalova MS, Vikulova OK, Smetanina SA, et al. Association of polymorphic markers of genes FTO, KCNJ11, CDKAL1 SLC30A8, and CDKN2B with type 2 diabetes mellitus in the Russian population. Peer J. 2017;5:e3414.

5. Song M, Zhao F, Ran L, Dolikun M, Wu L, Ge S, Dong H, Gao Q, Zhai Y, Zhang $L$, et al. The Uyghur population and genetic susceptibility to type 2 diabetes: potential role for variants in CDKAL1, JAZF1, and IGF1 genes. Omics. 2015;19:230-7.

6. Kamiński A, Bogacz A, Górska-Paukszta M, Seremak-Mrozikiewicz A, Czerny B. Correlation of rs749292 and rs700518 polymorphisms in the aromatase gene (CYP19A1) with osteoporosis in postmenopausal polish women. Adv Clin Exp Med. 2019;28:1067-71.

7. Hosseini E, Shahhoseini M, Afsharian P, Karimian L, Ashrafi M, Mehraein F, Afatoonian R. Role of epigenetic modifications in the aberrant CYP19A1 gene expression in polycystic ovary syndrome. Arch Med Sci. 2019;15:887-95.

8. Shiota M, Fujimoto N, Tsukahara S, Ushijima M, Takeuchi A, Kashiwagi E, Inokuchi J, Tatsugami K, Uchiumi T, Eto M. The impact of genetic polymorphism on CYP19A1 in androgen-deprivation therapy among Japanese men. Cancer Chemother Pharmacol. 2019:83:933-8.

9. Artigalás O, Vanni T, Hutz MH, Ashton-Prolla P, Schwartz IV. Influence of CYP19A1 polymorphisms on the treatment of breast cancer with aromatase inhibitors: a systematic review and meta-analysis. BMC Med. 2015;13:139.

10. Meng Y, Adi D, Wu Y, Wang Y, Abudoukelimu M, Huang D, Ma X, Liu C, Wang T, Liu F, et al. CYP19A1 polymorphisms associated with coronary artery disease and circulating sex hormone levels in a Chinese population. Oncotarget. 2017;8:97101-13.

11. Coban N, Onat A, Guclu-Geyik F, Can G, Erginel-Unaltuna N. Sex- and obesity-specific Association of Aromatase (CYP19A1) gene variant with Apolipoprotein B and hypertension. Arch Med Res. 2015;46:564-71.

12. Kadioglu E, Altun B, Ipek Ç, Döğer E, Bideci A, Attaran H, Çok I. The role of DENND1A and CYP19A1 gene variants in individual susceptibility to obesity in Turkish population-a preliminary study. Mol Biol Rep. 2018;45:2193-9.

13. Qi GZ, Zhang ZY, Wang X, Yin SJ, Lou YQ, Zhang GL. Functional allele and genotype frequencies of CYP1A2, CYP2B6 and iNOS among mainland Chinese Tibetan, Mongolian, Uygur and Han populations. J Clin Pharm Ther. 2016:41:84-91.

14. Arici M, Özhan G. The genetic profiles of CYP1A1, CYP1A2 and CYP2E1 enzymes as susceptibility factor in xenobiotic toxicity in Turkish population. Saudi Pharm J. 2017;25:294-7.

15. Koonrungsesomboon N, Khatsri R, Wongchompoo P, Teekachunhatean S. The impact of genetic polymorphisms on CYP1A2 activity in humans: a systematic review and meta-analysis. Pharmacogenomics J. 2018;18:760-8.

16. Adehin A, Bolaji OO. Polymorphisms of CYP1A2 and CYP2A6 activity: phenotypes and the effect of age and sex in a Nigerian population. Drug Metab Pers Ther. 2015:30:203-10.

17. Ren Y, Liu F, Shi X, Geng T, Yuan D, Wang L, Kang L, Jin T, Chen C. Investigation of the major cytochrome P450 1A2 genetic variant in a healthy Tibetan population in China. Mol Med Rep. 2017;16:573-80.

18. Jorge-Nebert LF, Zhang G, Wilson KM, Jiang Z, Butler R, Gluckman JL, Pinney SM, Nebert DW. Head-and-neck squamous cell carcinoma risk in smokers: no association detected between phenotype and AHR, CYP1A1, CYP1A2, or CYP1B1 genotype. Hum Genomics. 2016;10:39.
19. de Brito RB, de Carvalho Araújo L, Diniz MJA, de Castro Georg R, Nabout JC, Vianelo RP, da Silva Santos R, da Silva Cruz AH, Ghedini PC. The CYP1A2 $-163 C>$ a polymorphism is associated with super-refractory schizophrenia. Schizophr Res. 2015;169:502-3.

20. Gravel S, Chiasson JL, Turgeon J, Grangeon A, Michaud V. Modulation of CYP450 activities in patients with type 2 diabetes. Clin Pharmacol Ther. 2019;106:1280-9.

21. Urry E, Jetter A, Landolt HP. Assessment of CYP1A2 enzyme activity in relation to type-2 diabetes and habitual caffeine intake. Nutr Metab (Lond). 2016;13:66.

22. Wang H, Yao J, Yin X, Guo X, Yin J, Qu H, Sun Q. Organisational and individual characteristics associated with glycaemic control among patients with type 2 diabetes: cross-sectional study in China. BMJ Open. 2020;10: e036331.

23. Cai Q, Zheng J, Bai M, He X, Wang L, He Y, Yuan D, Huang T, Zhao J, Wu Y, et al. Genetic variations of CYP19A1 gene and stroke susceptibility: a casecontrol study in the Chinese Han population. J Cardiovasc Pharmacol. 2020; 75:344-50.

24. Kopp TI, Jensen DM, Ravn-Haren G, Cohen A, Sommer HM, Dragsted LO, Tjonneland A, Hougaard DM, Vogel U. Alcohol-related breast cancer in postmenopausal women - effect of CYP19A1, PPARG and PPARGC1A polymorphisms on female sex-hormone levels and interaction with alcohol consumption and NSAID usage in a nested case-control study and a randomised controlled trial. BMC Cancer. 2016;16:283.

25. Hao Y, Liu X, Lu X, Yang X, Wang L, Chen S, Li H, Li J, Cao J, Chen J, et al. Genome-wide association study in Han Chinese identifies three novel loci for human height. Hum Genet. 2013;132:681-9.

26. Bai $X$, Xie J, Sun S, Zhang $X$, Jiang $Y$, Pang $D$. The associations of genetic polymorphisms in CYP1A2 and CYP3A4 with clinical outcomes of breast cancer patients in northern China. Oncotarget. 2017;8:38367-77.

27. Zhu Y, Zhang N, Ren D, Bi Y, Xu F, Niu W, Sun Q, Guo Z, Yuan R, Yuan F, et al. CYP1A2 genetic polymorphism is associated with treatment remission to antidepressant venlafaxine in Han Chinese population. Clin Neuropharmacol. 2019;42:32-6.

28. Wang D, Chen X, Fu M, Xu H, Li Z. Pharmacogenomics analysis in Chinese pediatric liver transplantation patients with renal toxicity induced by tacrolimus. Xenobiotica. 2020:50:488-93.

29. Umamaheswaran G, Dkhar SA, Kalaivani S, Anjana R, Revathy M, Jaharamma M, Shree KM, Kadambari D, Adithan C. Haplotype structures and functional polymorphic variants of the drug target enzyme aromatase (CYP19A1) in south Indian population. Med Oncol. 2013;30:665.

30. Mazzuca F, Botticelli A, Mazzotti E, La Torre M, Borro M, Marchetti L, Maddalena C, Gentile G, Simmaco M, Marchetti P. CYP19A1 genetic polymorphisms rs4646 and osteoporosis in patients treated with aromatase inhibitor-based adjuvant therapy. Eurasian J Med. 2016;48:10-4.

31. De Paoli M, Werstuck GH. Role of estrogen in type 1 and type 2 diabetes mellitus: a review of clinical and preclinical data. Can J Diabetes. 2020;44(5): 448-52.

32. Casiglia E, Tikhonoff V, Albertini F, Favaro J, Montagnana M, Danese E, Finatti F, Benati M, Mazza A, Dal Maso L, et al. Caffeine intake and abstract reasoning among 1374 unselected men and women from general population. Role of the $-163 \mathrm{C}>$ A polymorphism of CYP1A2 gene. Clin Nutr ESPEN. 2017:20:52-9.

33. Denden S, Bouden B, Haj Khelil A, Ben Chibani J, Hamdaoui MH. Gender and ethnicity modify the association between the CYP1A2 rs762551 polymorphism and habitual coffee intake: evidence from a meta-analysis. Genet Mol Res. 2016;15(2):gmr.15027487.

34. Stasiukonyte N, Liutkeviciene R, Vilkeviciute A, Banevicius M, Kriauciuniene L. Associations between Rs4244285 and Rs762551 gene polymorphisms and age-related macular degeneration. Ophthalmic Genet. 2017;38:357-64.

\section{Publisher's Note}

Springer Nature remains neutral with regard to jurisdictional claims in published maps and institutional affiliations. 